\title{
Changes in ocular astigmatism after superotemporal versus temporal clear corneal incision cataract surgery
}

\section{Qi Fan}

Eye \& ENT Hospital of Fudan University

\section{Dongjin Qian}

Eye \& ENT Hospital of Fudan University

Zhennan Zhao

Eye \& ENT Hospital of Fudan University

\section{Yongxiang Jiang}

Eye \& ENT Hospital of Fudan University

Yi Lu ( $\triangle$ luyieent@126.com )

Eye \& ENT Hospital of Fudan University

\section{Research Article}

Keywords: cataract surgery, corneal astigmatism, ocular residual astigmatism, surgically induced astigmatism

Posted Date: March 16th, 2021

DOl: https://doi.org/10.21203/rs.3.rs-311232/v1

License: (c) (i) This work is licensed under a Creative Commons Attribution 4.0 International License. Read Full License 


\section{Abstract \\ Background}

The incision site to choose to manage postoperative astigmatism during cataract surgery is still debated. This study investigated corneal and internal astigmatism changes after superotemporal versus temporal clear corneal incision cataract surgery.

\section{Methods}

Patients included were diagnosed between December 2019 and January 2020 with age-related cataract with corneal astigmatism < 1.5 diopters (D) and were divided into two groups: Right Eye Group (R Group, superotemporal incision) and Left Eye Group (L Group, temporal incision). Uncorrected visual acuity, manifest refraction, corneal topography, anterior segment optical coherence tomography were performed pre- and 6 months postoperatively. Total ocular astigmatism, corneal astigmatism, surgically induced corneal astigmatism (SICA), non-corneal ocular residual astigmatism (N-CORA), postoperative intraocular lens (IOL) decentration, and tilt were analysed.

\section{Results}

Thirty-eight subjects were included: 21, R Group; 17, L Group. After surgery, the N-CORA decreased significantly from $1.17 \pm 0.72 \mathrm{D}$ to $0.73 \pm 0.47 \mathrm{D}$ in all patients $(P=0.001), 1.03 \pm 0.52 \mathrm{D}$ to $0.70 \pm 0.40 \mathrm{D}$ in the R Group $(P=0.005)$, and $1.35 \pm 0.90 D$ to $0.78 \pm 0.55 D$ in the $L$ Group $(P=0.033)$. Significant differences between the $\mathrm{R}$ and $\mathrm{L}$ groups were found in the postoperative meridian of anterior corneal astigmatism $(75.95 \pm 52.50$ vs $116.79 \pm 47.29 ; P=0.017)$, total corneal astigmatism $(51.65 \pm 42.75$ vs $95.20 \pm 57.32 ; \mathrm{P}=0.011)$, J45 change vector of SICA in the anterior cornea $(-0.10 \pm 0.18$ vs $0.00 \pm 0.11 ; P$ $=0.048)$, and total cornea surface $(-0.14 \pm 0.17$ vs $0.03 \pm 0.12 ; P=0.001)$. IOL decentration, tilt, and the meridian of IOL tilt were not significantly correlated with N-CORA.

\section{Conclusions}

The N-CORA significantly decreased after cataract surgery. Superotemporal and temporal incisions can cause differences in the meridian components of oblique astigmatism but will not have a significant effect on the magnitude of corneal astigmatism.

\section{Background}

With advances in surgical techniques and improved precise postoperative refraction predication, modern cataract surgery can be considered as a refractive surgery. ${ }^{1}$ Post-operative refraction within 0.50 diopter (D) allowed for improved uncorrected visual acuity and increased patient satisfaction. It has been 
reported that $90 \%$ of patients had postoperative astigmatism $\geq 0.5 \mathrm{D}$ and $58 \% \geq 1.0 \mathrm{D}$ and visual acuity tended to worsen postoperatively with increased astigmatism. ${ }^{2}$ Hence, controlling postoperative astigmatism is one of the main goals of cataract surgery to increase patient satisfaction.

There are many effective strategies for controlling astigmatism in cataract surgery, including different incision sites (on-axis, on-axis opposite clear corneal incisions, and others), limbal relaxing incisions (LRI) utilising either a blade or a femtosecond laser, and toric intraocular lenses (IOL). The on-axis incision technique is a useful way to reduce astigmatisms $<1.5 \mathrm{D},{ }^{3}$ and the effect can be enhanced by opposite clear corneal incisions ${ }^{4}$ (on-axis opposite clear corneal incisions, adding a second clear corneal incision diametrically opposite on the steep meridian). LRIs have been found to be efficacious and easy to perform, while a femtosecond laser achieved a higher correction index than a blade ${ }^{5}$ and with lower complication rates. ${ }^{6}$ Toric IOLs may provide the most reliable and effective lower amount of residual astigmatism. $^{7}$

A previous study revealed that $22.2 \%$ of patients had corneal astigmatism $>1.5 \mathrm{D}$ during cataract surgery. ${ }^{8}$ Toric IOL and femtosecond laser-assisted astigmatic keratotomy are useful methods to correct moderate and even higher levels of astigmatism. However, for the correction of low to moderate astigmatism, which accounts for the majority of corneal astigmatism, they will impose a substantial economic burden on the country and patients, especially in developing countries. However, the choice of the incision site is a suitable method without additional equipment and economic burden.

Careful preoperative planning of the incision location is essential to avoid making the preoperative exited corneal astigmatism worse and sometimes can even reduce it. Among the different incision sites, the onaxis technique is the most effective way to reduce corneal astigmatism. Temporal approaches present a lower frequency of surgically induced astigmatism. ${ }^{9}$ However, it is difficult to perform these two options in certain situations; for example, deep-set eyes or eyes with certain oblique astigmatisms. High-volume right-handed cataract surgeons may prefer to choose the superior or superotemporal incision owing to more comfort and better exposure of the surgical field. Hence, there is still debate on which incision site to choose to manage postoperative astigmatism during cataract surgery.

In this study, the changes in ocular astigmatism after superotemporal versus temporal clear corneal incision cataract surgery in patients with low to moderate corneal astigmatism were analysed and support for the choice of incision site by surgeons during modern cataract surgery was provided.

\section{Methods}

This study was approved by the Ethics Committee of the Eye \& Ear, Nose, and Throat (ENT) Hospital of Fudan University and adhered to the Declaration of Helsinki. Informed consent was obtained from all subjects included in this study.

\section{Patients}


Patients included in this retrospective study were recruited from the Eye Institute and Department of Ophthalmology, Eye \& ENT Hospital, Fudan University between December 2019 and January 2020. All patients were diagnosed with age-related cataract with corneal astigmatism $<1.5 \mathrm{D}$. Patients with systemic diseases, other ocular diseases, and/or a history of previous intraocular surgery were excluded.

All surgeries were performed by one experienced surgeon ( $\mathrm{Dr}$ Yi Lu). According to the primary clear corneal incision position commonly used by $\mathrm{Dr}$ Lu, patients were divided into the right eye group ( $\mathrm{R}$ Group, with a main 2.6-mm clear corneal incision located on the superotemporal side) and left eye group ( $\mathrm{L}$ Group, with a main 2.6-mm clear corneal incision located on the temporal side).

\section{Surgical technique}

All the surgeries were performed under topical anaesthesia with Oxybuprocaine Hydrochloride Eye Drops (Santen Pharmaceutical Co., Ltd., Japan) after pupils were dilated with Tropicamide Phenylephrine Eye Drops (Santen Pharmaceutical Co., Ltd., Japan). A main 2.6-mm clear corneal incision was made, followed by a 1-mm paracentesis incision that spaced 90 degrees from the main incision. Once DisCoVisc (sodium chondroitin sulfate-sodium hyaluronate, Alcon, USA) was injected into the anterior chamber, a capsulorhexis was performed in a 5.0-6.0-mm diameter circle. Then, a hydrodissection with balanced salt solution was performed. Phacoemulsification and aspiration were performed using the CENTURION vision system phacoemulsification platform. After complete removal of lens, the capsular bag and anterior chamber were injected with DisCoVisc. A foldable intraocular lens (ZCB00, Johnson \& Johnson Surgical Vision, Inc., Santa Ana, CA, USA), which aimed for postoperative refraction between 0 and -0.50 diopters, was injected into the capsular bag through the main incision. After the DisCoVisc was removed, the incisions were hydrated with balanced salt solution.

Post-operatively, 0.5\% Levofloxacin Eye Drops (Santen Pharmaceutical Co., Ltd., Japan) and 1\% Prednisolone Acetate Ophthalmic Suspension (Allergen Pharmaceutical Ireland, Ireland) were administered four times daily for 2 weeks and 1\% Pranoprofen Eye Drops (Senju Pharmaceutical Co. Ltd., Japan) four times daily for 1 month.

\section{Ophthalmologic examination}

Ophthalmologic examinations were performed before the surgery and at 1, 7 days and 1,6 months after surgery. At the pre-operative and 6-month post-operative visits, all patients had a complete ophthalmologic examination that included uncorrected visual acuity (LogMar unit), manifest refraction, slit-lamp examination, corneal topography examination (Pentacam HR; OCULUS Optikgerate GmbH, Wetzlar, Germany), anterior segment optical coherence tomography (AS-OCT, CASIA SS-1000; Tomey Corporation, Nagoya, Japan), and dilated fundus examination. At other scheduled study visits, all patients had a brief ophthalmologic examination that included uncorrected visual acuity (LogMar unit), manifest refraction and slit-lamp examination.

\section{Measurements and vector analysis of astigmatism}


The ocular astigmatism was obtained from the manifest refraction and was converted to the corneal plane using a vertex of $12.0 \mathrm{~mm}$.

Corneal astigmatism was obtained using corneal topography performed by Pentacam HR. A single operator (Qi Fan) acquired all the topographies using the automatic release mode of the Scheimpflug device. Three measurements were averaged for each result. The obtained data included the magnitude and meridian of anterior corneal surface astigmatism, posterior corneal surface astigmatism, and total corneal astigmatism.

The non-corneal ocular residual astigmatism (N-CORA) and surgically induced corneal astigmatism (SICA) were assessed using a method established by Alpins. ${ }^{10,11}$ A Fourier transformation was performed to decompose the cylinder notation into vertical-horizontal (represents astigmatism with axes at 180 degrees and 90 degrees, J0) and oblique (represents astigmatism with axes at 45 degrees and 135 degrees, J45) astigmatic change components. ${ }^{12}$ The $\mathrm{J} 0$ and $\mathrm{J} 45$ components are calculated as follows: $\mathrm{J} 0=(-\mathrm{C} / 2) \cos 2 \alpha ; \mathrm{J} 45=(-\mathrm{C} / 2) \sin 2 \alpha$, where $\mathrm{C}$ is the magnitude of cylinder power and $\mathrm{a}$ is the axis in radians. The N-CORA was determined as the vector difference between the preoperative ocular refractive astigmatism (corneal plane) and the topographic astigmatism of the total cornea surface. The SICA was determined as the change vector from postoperative astigmatism to preoperative astigmatism in the anterior, posterior, and total cornea surface.

\section{Intraocular lens tilt and decentration examination}

IOL tilt and decentration examinations were performed using AS-OCT. After pupils were dilated with Tropicamide Phenylephrine Eye Drops (Santen Pharmaceutical Co., Ltd., Japan), the AS-OCT examination was conducted with the 3D angle analysis scan mode using the auto-alignment function by the same operator (Dr. Qi Fan). After 3D-reconstruction of consecutive meridional scans, the anterior and posterior surfaces of the IOL were imaged referencing the position of the iris. The cross-sectional images with the most apparent decentration and tilt of the IOL were selected, and CASIA built-in software was used to calculate the IOL decentration and tilt angle. The angle $(\theta)$ between the pupillary plane and the IOL plane was presented as IOL tilt. The vertical distance between the centre points of the pupillary plane and the IOL plane was recorded as IOL decentration. The average result of three scans was recorded as the final result.

\section{Statistical analysis}

Statistical analyses were performed using SPSS software (SPSS version 25.0; SPSS, Inc., Chicago, IL). Differences in continuous variables were analysed using the paired/unpaired t-test, while for the categorical variables, the chi-square test was used. Linear regression analysis was performed to identify the factors correlated with N-CORA. P values $<0.05$ were considered significant.

\section{Results}


A total of 38 subjects (female: 25; male: 13) were included in this study, with 21 (female: 14; male: 7) included in the R Group and 17 (female: 11; male: 6) included in the L Group. Table 1 shows the patients' basic clinical characteristics. The mean age of all subjects was $68.58 \pm 10.89$ years, with a mean age of $69.29 \pm 12.54$ years in the $R$ Group and $67.71 \pm 8.75$ years in the $L$ Group. There were no significant differences in age $(P=0.663)$ and $\operatorname{sex}(P=0.899)$ between the groups.

Table 1

Baseline clinical characteristics

\begin{tabular}{|c|c|c|c|c|}
\hline & All patient & $\mathrm{R}$ group & L group & $\begin{array}{l}P \text { value } \\
\text { between } R \text { and } L \\
\text { groups }\end{array}$ \\
\hline Age & $\begin{array}{l}68.58 \pm \\
10.89\end{array}$ & $\begin{array}{l}69.29 \pm \\
12.54\end{array}$ & $\begin{array}{l}67.71 \pm \\
8.75\end{array}$ & 0.663 \\
\hline Sex & & & & 0.899 \\
\hline Male & $13(34.2 \%)$ & $7(33.3 \%)$ & $6(35.3 \%)$ & \\
\hline Female & $25(65.8 \%)$ & $14(66.7 \%)$ & $11(64.7 \%)$ & \\
\hline \multicolumn{5}{|l|}{$\begin{array}{l}\text { Uncorrected visual acuity (LogMar } \\
\text { unit) }\end{array}$} \\
\hline Pre-operation & $0.72 \pm 0.57$ & $0.78 \pm 0.69$ & $\begin{array}{l}0.64 \pm \\
0.37\end{array}$ & 0.587 \\
\hline Post-operation & $0.06 \pm 0.08$ & $0.07 \pm 0.08$ & $\begin{array}{l}0.05 \pm \\
0.07\end{array}$ & 0.899 \\
\hline $\begin{array}{l}\mathrm{P} \text { value between pre- and post- } \\
\text { operation }\end{array}$ & $<0.001$ & $<0.001$ & $<0.001$ & \\
\hline
\end{tabular}

The uncorrected visual acuity was significantly improved from $0.72 \pm 0.57$ pre-operatively to $0.06 \pm 0.08$ post-operatively in all patients $(P<0.001)$. Significantly improved uncorrected visual acuity was also found in the $\mathrm{R}$ Group (from $0.78 \pm 0.69$ pre-operatively to $0.07 \pm 0.08$ postoperatively, $\mathrm{P}<0.001$ ) and $\mathrm{L}$ Group (from $0.64 \pm 0.37$ preoperatively to $0.05 \pm 0.07$ postoperatively, $\mathrm{P}<0.001$ ). No significant difference was found in preoperative $(P=0.587)$ and postoperative $(P=0.899)$ uncorrected visual acuity between the $R$ and $L$ Groups.

Patients' pre-and postoperative astigmatism are shown in Fig. 1. In terms of the magnitude of astigmatism, postoperative corneal astigmatism (anterior, posterior, and total corneal surface) and total ocular astigmatism were not significantly different before surgery. In contrast, postoperative N-CORA was significantly decreased than that preoperatively, that is, from $1.17 \pm 0.72 \mathrm{D}$ to $0.73 \pm 0.47 \mathrm{D}$ in all patients $(P=0.001), 1.03 \pm 0.52 \mathrm{D}$ to $0.70 \pm 0.40 \mathrm{D}$ in the $R$ Group $(P=0.005)$, and $1.35 \pm 0.90 \mathrm{D}$ to $0.78 \pm 0.55 \mathrm{D}$ in the $L$ Group $(P=0.033)$. In terms of the meridian of astigmatism, there was no significant difference pre- 
and postoperatively, whether in corneal astigmatism (anterior, posterior, and total corneal surface), $\mathrm{N}$ CORA or total ocular astigmatism.

The pre- and postoperative astigmatism in the $\mathrm{R}$ and $\mathrm{L}$ Groups are shown in Fig. 2. There was no significant difference between the two groups pre-operatively, whether in magnitude or meridian of corneal astigmatism (anterior, posterior, and total corneal surface), N-CORA and total ocular astigmatism. After cataract surgery, significant differences were found between the $R$ and $L$ groups in the meridian of anterior corneal astigmatism $(75.95 \pm 52.50$ vs $116.79 \pm 47.29, \mathrm{P}=0.017)$ and total corneal astigmatism $(51.65 \pm 42.75$ vs $95.20 \pm 57.32, P=0.011)$. There was no significant difference in the magnitude of corneal, N-CORA and total ocular astigmatism.

Surgically induced corneal astigmatism in the R and L Groups are shown in Fig. 3. There is no significant difference between the two groups in the magnitude and meridian of SICA. However, when analysing the vertical-horizontal and oblique astigmatic vector change components, significant differences were found between the $\mathrm{R}$ and $\mathrm{L}$ groups in $\mathrm{J} 45$ of surgically induced corneal astigmatism in the anterior cornea $(-0.10 \pm 0.18$ vs $0.00 \pm 0.11, P=0.048)$ and total cornea surface $(-0.14 \pm 0.17$ vs $0.03 \pm 0.12, P=0.001)$.

The measurement process of IOL decentration and tilt is shown in Fig. 4. Results of all patients' IOL decentration and tilt are shown in Table 2. The average value of IOL decentration was $0.09 \pm 0.10 \mathrm{~mm}$, that is, from $0.01 \mathrm{~mm}$ to $0.44 \mathrm{~mm}$. The magnitude of IOL tilt was $1.78 \pm 1.96$ degree, that is, from 0.20 degrees to 10.90 degrees. The meridian of IOL tilt was $61.82 \pm 40.39$, along an axis of 3 to 170 . IOL decentration, IOL tilt and the meridian of IOL tilt were not significantly correlated with N-CORA on linear regression analysis.

Table 2

Results of all patients' intraocular lens decentration and tilt

\begin{tabular}{|lllllll|}
\hline & Mean & $\begin{array}{l}\text { Standard } \\
\text { deviation }\end{array}$ & Minimum & Max & $\begin{array}{l}\text { P value } \\
\text { (correlated with } \\
\text { magnitude of N- } \\
\text { CORA) }\end{array}$ & $\begin{array}{l}\text { P value (correlated } \\
\text { with meridian of N- } \\
\text { CORA) }\end{array}$ \\
\hline $\begin{array}{l}\text { IOL } \\
\text { decentration }\end{array}$ & 0.09 & 0.10 & 0.01 & 0.44 & 0.86 & 0.90 \\
\hline IOL tilt & 1.78 & 1.96 & 0.20 & 10.90 & 0.69 & 0.20 \\
\hline $\begin{array}{l}\text { Meridian of } \\
\text { IOL tilt }\end{array}$ & 61.82 & 40.39 & 3.00 & 170.00 & 0.41 & 0.35 \\
\hline
\end{tabular}

\section{Discussion}

Modern cataract surgery can be an effective refractive procedure. There is a growing demand for this surgery considering the influence of astigmatism on uncorrected visual acuity and minimizing it during cataract surgery. This study observed the changes in ocular astigmatism in patients with low to moderate 
corneal astigmatism after cataract surgery. It analysed the differences in astigmatism changes caused by the temporal and superiortemporal corneal incisions.

Lenticular astigmatism has been considered the most common cause of internal astigmatism. ${ }^{13}$ Toam Katz et al. ${ }^{14}$ found that the magnitude of the ocular residual astigmatism (ORA) decreased after cataract surgery. Consistent with Toam Katz's study, this study also found that the magnitude of non-corneal ocular residual astigmatism significantly decreased post-operatively, that is, from a mean magnitude of 1.17D orientated along an axis of 51.44 to a mean magnitude of $0.73 \mathrm{D}$ orientated along an axis of 46.58 . As known, astigmatism arising from the anterior corneal and anterior lens surfaces is almost completely compensated for by the posterior corneal and posterior lens surface in young healthy subjects. ${ }^{15}$ In the process of cataract formation, as the lens opacity increases, internal astigmatism caused by the lens opacity may gradually increase. The posterior lens surface cannot compensate for it. Therefore, after cataract extraction, the internal astigmatism of cataract patients decreases significantly.

It is believed that ORA in pseudophakic eyes mainly results from the posterior corneal surface. ${ }^{14} \mathrm{~A}$ significant but weak correlation was found between the magnitudes of internal astigmatism and posterior corneal astigmatism in the pseudophakic eyes. ${ }^{16}$ However, calculation of ORA in previous studies was determined from the vector difference between the refractive cylinder and the anterior topographic astigmatism, which did not exclude the influence of the posterior surface of the cornea. In this study, the N-CORA, which was determined from the vector difference between the refractive cylinder and the total corneal surface topographic astigmatism, was calculated. The magnitude of corneal astigmatism, including anterior, posterior, and total cornea surface, remained stable after surgery. Moreover, to remove the influence of corneal astigmatism, there was still residual astigmatism of 0.73D. Hence, ORA in pseudophakic eyes perhaps also resulted from the implanted IOL.

Previous studies have shown that the tilt of the IOL can induce ORA, and IOL-induced astigmatism increased with increasing IOL tilt. ${ }^{17}$ Five degrees of IOL tilt induced astigmatism from $0.08 \mathrm{D}$ to $0.14 \mathrm{D}$ and ten degrees of $I O L$ tilt induced astigmatism from $0.33 \mathrm{D}$ to $0.56 \mathrm{D}$. In this study, the average tilt of IOL was 1.78 degrees, which was small. At the same time, variations in the N-CORA according to IOL tilt and IOL decentration were not significant. Hence, an internal astigmatism caused by this degree of IOL tilt may be relatively small. The ORA in pseudophakic eyes might also be the main result of the shrinkage and proliferation of the posterior capsule during the 6 months after cataract surgery.

Incision sizes have a significant influence on postoperative astigmatism, and a 3-mm temporal incision is considered astigmatically neutral. ${ }^{18}$ Many previous studied demonstrated that surgically induced astigmatism (SIA) reduced significantly when the incision size was reduced from $3.0 \mathrm{~mm}$ to $2.2 \mathrm{~mm} .{ }^{19}$ However, this difference decreases over a more extended period of time. ${ }^{20}$ At the same time, this significant decrease was not found when the reduction of incision size from $2.6 \mathrm{~mm}$ to $2.2 \mathrm{~mm}$ with respect that SIA was similar between the $2.2-\mathrm{mm}$ and $2.6-\mathrm{mm}$ groups. ${ }^{21} \mathrm{In}$ this study, cataract surgery using a 2.6-mm incision size and follow-up for 6 months after the operation was performed. No 
significant changes in postoperative astigmatism compared with preoperative were observed, indicating that corneal astigmatism did not worsen postoperatively using the $2.6-\mathrm{mm}$ incision size, no matter whether it is using the superotemporal or temporal clear corneal incision.

Cataract surgery can be performed with clear corneal incisions in several sites, and different incision sites can induce different degrees of SIA. A nasal clear incision was usually not used because it often associated with a higher SIA. Though an on-axis incision method is the most effective method for astigmatism correction, temporal and superotemporal sites were more popular than on-axis owing to better exposure of the surgical field and more comfort while operating. Hence, in this study, the differences in astigmatism change caused by the superotemporal and temporal incisions were compared.

Previous studies generally considered that temporal incisions are to be associated with less SIA. However, some studies have demonstrated ${ }^{22}$ that superior and temporal incision sites make no difference in regular and irregular SIA after surgery. In this study, a significant difference in J45 of surgically induced corneal astigmatism at the anterior cornea and total cornea surface between the $\mathrm{R}$ and $\mathrm{L}$ groups was found. A significant difference in the meridian of postoperative anterior corneal and postoperative total corneal surface astigmatism was also found. This significant difference represented the difference in oblique astigmatic change components with axes at 45 degrees and 135 degrees. However, this difference only causes a change in the astigmatism axis after surgery but has no significant effect on the total magnitude of astigmatism. This finding is because no significant difference between the two groups in the magnitude of corneal SICA persists after considering J0. There is no difference in the magnitude of corneal astigmatism postoperatively. Hence, superotemporal and temporal incisions could induce meridian differences in oblique astigmatic change components. And this difference is ultimately presented in the significant difference in the meridian of postoperative corneal astigmatism in the anterior corneal and total corneal surface. However, it does not influence the magnitude of each astigmatism component.

\section{Conclusions}

In conclusion, the N-CORA significantly decreased after cataract surgery, which may result from the shrinkage and proliferation of the posterior capsule. Superotemporal and temporal incisions could cause differences in the meridian components of oblique astigmatism. Corneal astigmatism did not worsen postoperatively using the $2.6-\mathrm{mm}$ incision size, regardless of using the superotemporal or temporal clear corneal incision.

\section{Abbreviations}

LRI: limbal relaxing incisions; SICA: corneal astigmatism; N-CORA: non-corneal ocular residual astigmatism; IOL: intraocular lens. 


\section{Declarations}

\section{Ethics approval and consent to participate}

All procedures were performed in accordance with the Declaration of Helsinki and was approved by the Ethics Committee of the Eye \& Ear, Nose, and Throat (ENT) Hospital of Fudan University. Informed consent was obtained from all subjects included in this study.

\section{Consent to publish}

Not applicable

\section{Availability of data and materials}

The datasets used and analysed during the current study are available from the corresponding author on reasonable request.

\section{Competing interests}

The authors declare that they have no competing interests.

\section{Funding}

This work was supported by the National Natural Science Foundation of the People's Republic of China (NSFC, No. 81600718). The funding organization had no role in the design or conduct of this research.

\section{Authors' contributions}

Yongxiang Jiang and Yi Lu designed the research; Qi Fan and Dongjin Qian collected the data; Qi Fan and Zhennan Zhao analyzed the data. Qi Fan wrote the manuscript. Yongxiang Jiang and Yi Lu critically revised the manuscript. Authors' Contributions Yongxiang Jiang and Yi Lu contributed equally to this work.

\section{Acknowledgements}

Not applicable.

\section{References}

1. Olson RJ, Mamalis N, Werner L. Apple DJ. Cataract treatment in the beginning of the 21 st century. Am J Ophthalmol. 2003;136:146-54

2. Day AC, Dhariwal M, Keith MS, Ender F, Perez Vives C, Miglio C, Zou L, Anderson DF. Distribution of preoperative and postoperative astigmatism in a large population of patients undergoing cataract surgery in the UK. Br J Ophthalmol. 2019;103:993-1000. 
3. Hashemi H, Khabazkhoob M, Soroush S, Shariati R, Miraftab M, Yekta A. The location of incision in cataract surgery and its impact on induced astigmatism. Curr Opin Ophthalmol. 2016;27:58-64.

4. Lever J, Dahan E. Opposite clear corneal incisions to correct pre-existing astigmatism in cataract surgery. J Cataract Refract Surg. 2000; 26:803-05.

5. Roberts HW, Wagh VK, Sullivan DL, Archer TJ, O'Brart DPS. Refractive outcomes after limbal relaxing incisions or femtosecond laser arcuate keratotomy to manage corneal astigmatism at the time of cataract surgery. J Cataract Refract Surg. 2018;44:955-963.

6. Vickers LA, Gupta PK. Femtosecond laser-assisted keratotomy. Curr Opin Ophthalmol. 2016;27:27784.

7. Kessel L, Andresen J, Tendal B, Erngaard D, Flesner P, Hjortdal J. Toric Intraocular Lenses in the Correction of Astigmatism During Cataract Surgery: A Systematic Review and Meta-analysis. Ophthalmology. 2016;123:275-86.

8. Ferrer-Blasco T, Montés-Micó R, Peixoto-de-Matos SC, González-Méijome JM, Cerviño A. Prevalence of corneal astigmatism before cataract surgery. J Cataract Refract Surg. 2009;35:70-5.

9. Borasio E, Mehta JS, Maurino V. Surgically induced astigmatism after phacoemulsification in eyes with mild to moderate corneal astigmatism Temporal versus on-axis clear corneal incisions. J Cataract Refract Surg. 2006;32:565-72.

10. Alpins NA. New method of targeting vectors to treat astigmatism. J Cataract Refract Surg. 1997; 23:65-75.

11. Alpins N. Astigmatism analysis by the Alpins method. J Cataract Refract Surg. 2001; 27:31-49.

12. Holladay JT, Moran JR, Kezirian GM. Analysis of aggregate surgically induced refractive change, prediction error, and intraocular astigmatism. J Cataract Refract Surg. 2001;27:61-79.

13. Feizi S, Delfazayebaher S, Javadi MA. Agreement Between Internal Astigmatism and Posterior Corneal Astigmatism in Pseudophakic Eyes. J Refract Surg. 2018;34:379-86.

14. Katz T, Steinberg J, Druchkiv V, Linke SJ, Frings A. Ocular residual astigmatism (ORA) in pre-cataract eyes prior to and after refractive lens exchange. Int Ophthalmol.2017;37:859-65.

15. M C Dunne,M E Elawad,D A Barnes. Measurement of astigmatism arising from the internal ocular surfaces. Acta Ophthalmol Scand.1996;74:14-20.

16. Feizi S, Delfazayebaher S, Javadi MA. Agreement Between Internal Astigmatism and Posterior Corneal Astigmatism in Pseudophakic Eyes. J Refract Surg. 2018;34:379-86.

17. Weikert MP, Golla A, Wang L. Astigmatism induced by intraocular lens tilt evaluated via ray tracing. J Cataract Refract Surg. 2018;44:745-49.

18. Zheng L, Merriam JC, Zaider M. Astigmatism and visual recovery after 'large incision' extracapsular cataract surgery and 'small' incisions for phacoemulsification. Trans Am Ophthalmol Soc. 1997;95:387-410

19. Luo L, Lin H, He M, Congdon N, Yang Y, Liu Y. Clinical evaluation of three incision size-dependent phacoemulsification systems. Am J Ophthalmol. 2012;153:831-39. 
20. Musanovic Z, Jusufovic V, Halibasica M, Zvornicanin J. Corneal astigmatism after micro-incision cataract operation. Med Arh. 2012;66:125-8.

21. Wang J, Zhang EK, Fan WY, Ma JX, Zhao PF. The effect of micro-incision and small-incision coaxial phaco-emulsification on corneal astigmatism. Clin Exp Ophthalmol. 2009;37:664-9.

22. Oshika T, Sugita G, Tanabe T, Tomidokoro A, Amano S. Regular and irregular astigmatism after superior versus temporal scleral incision cataract surgery. Ophthalmology. 2000;107:2049-53.

\section{Figures}

A

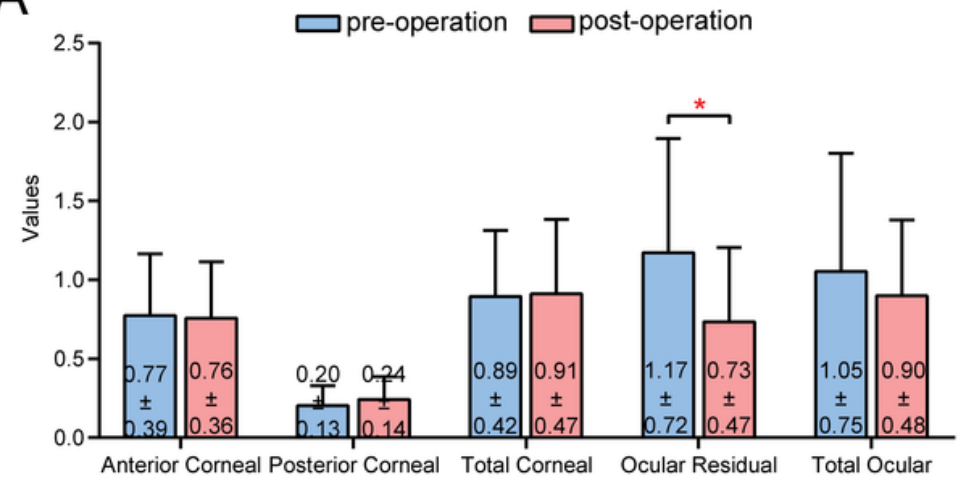

Magnitude of all patients' Astigmatism

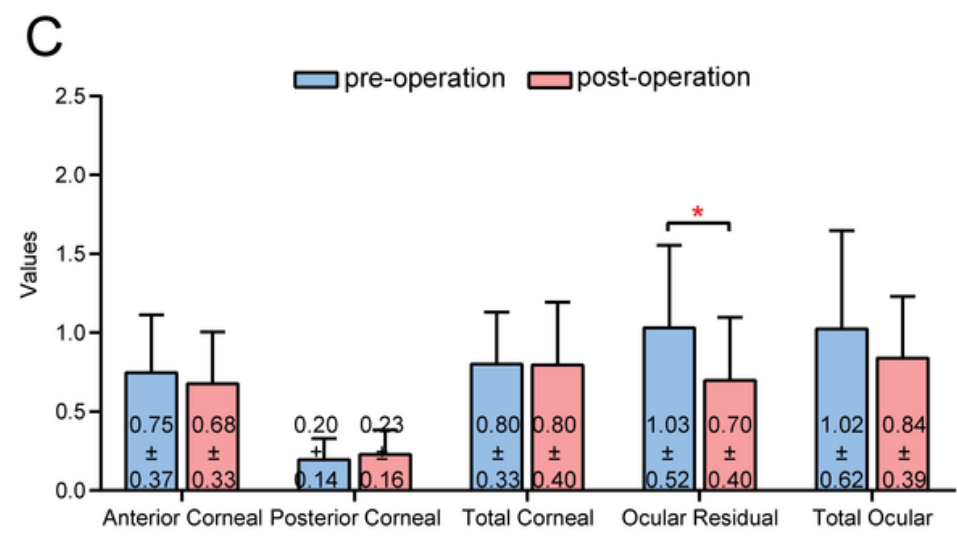

Magnitude of R Group's Astigmatism

E

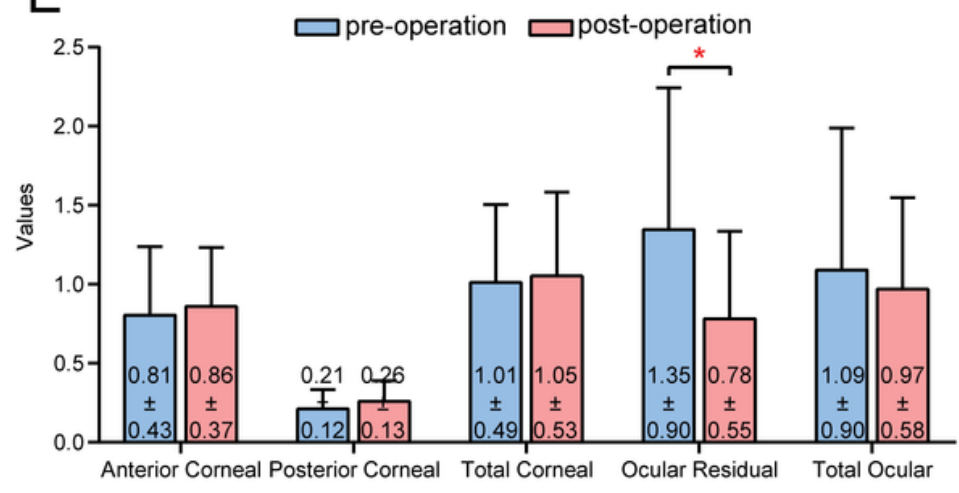

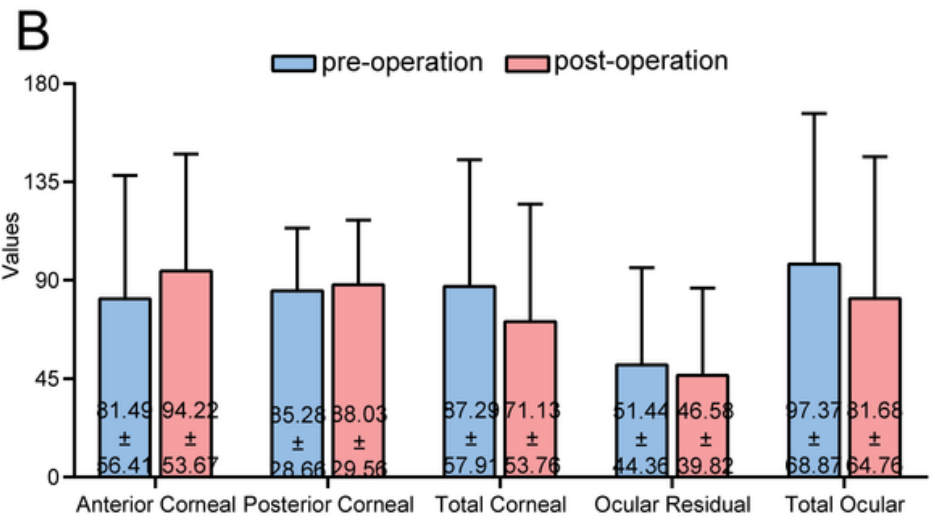

Meridian of all patients' Astigmatism

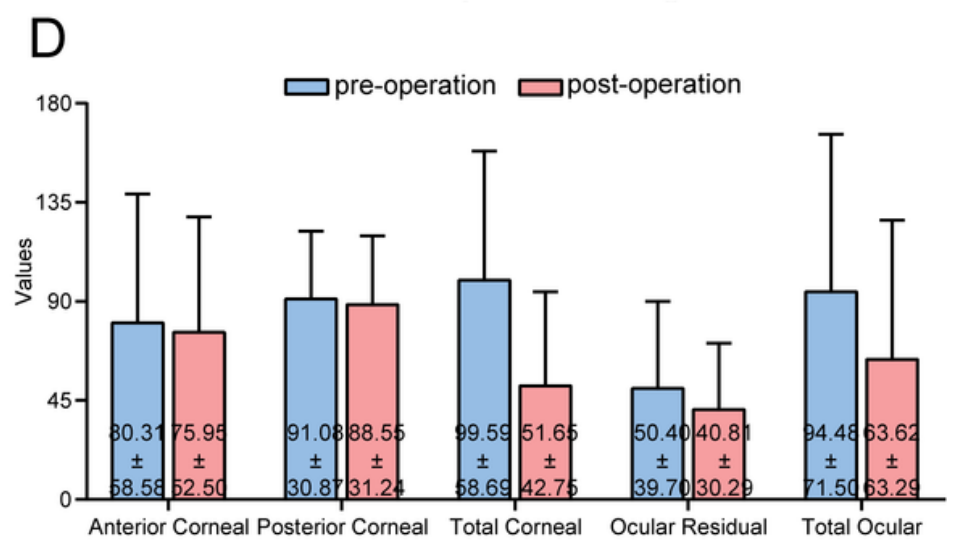

Meridian of R Group's Astigmatism

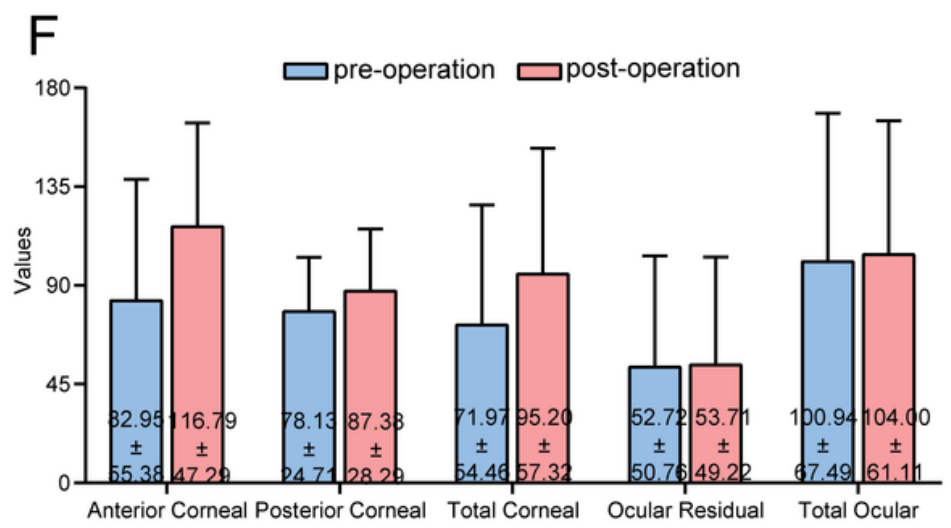


Figure 1

Patients' pre- and postoperative astigmatism in the anterior cornea, posterior cornea, total cornea; noncorneal ocular residual astigmatism; and total ocular astigmatism. A: Magnitude of astigmatism in all patients pre- and postoperatively; B: Meridian of astigmatism in all patients pre- and postoperatively; C: Magnitude of astigmatism in the R Group pre- and postoperatively; D: Meridian of astigmatism in the R Group pre- and postoperatively; E: Magnitude of astigmatism in the L Group pre- and postoperatively; F: Meridian of astigmatism in the L Group pre-and postoperatively. *statistically significant difference was found.

A

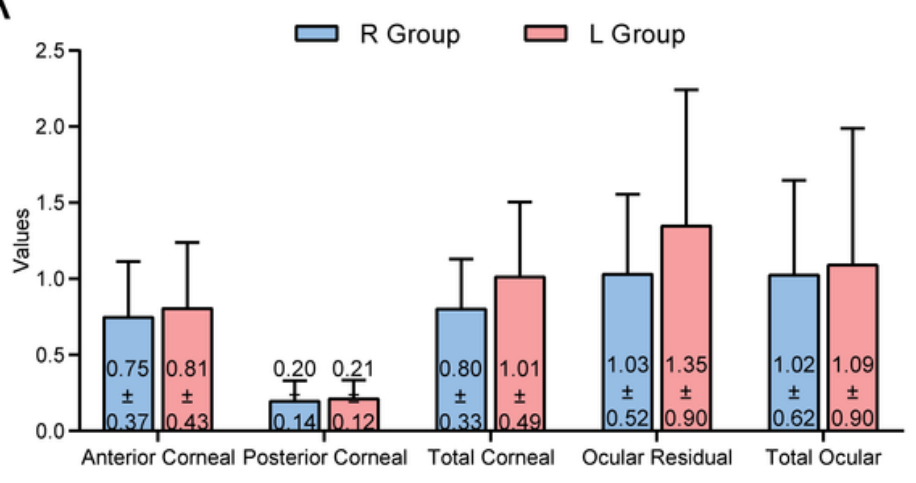

Magnitude of R and L Groups' Astigmatism Pre-operation

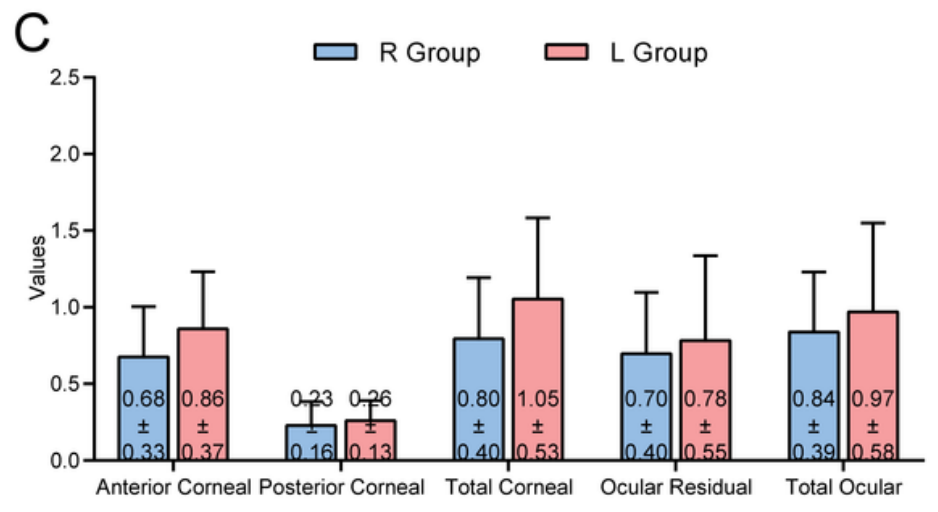

Magnitude of R and L Groups' Astigmatism Post-operation

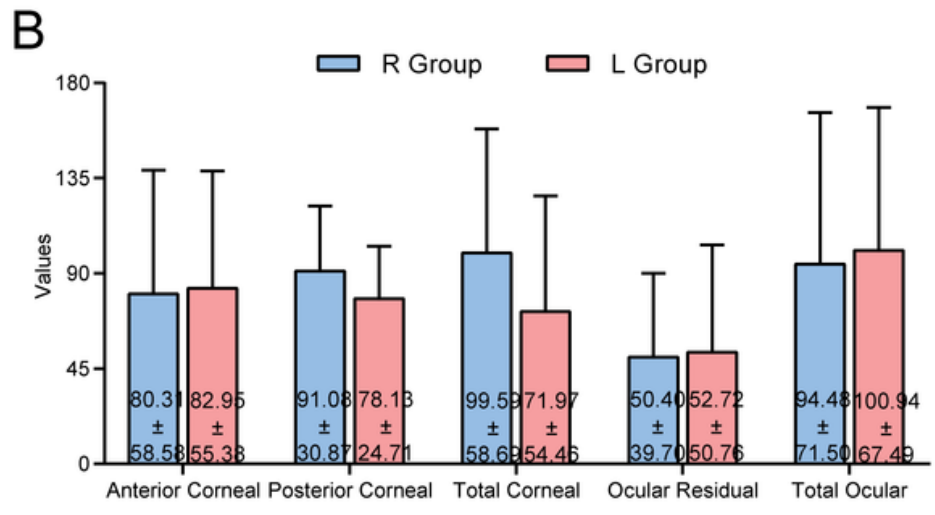

Meridian of R and L Groups' Astigmatism Pre-operation

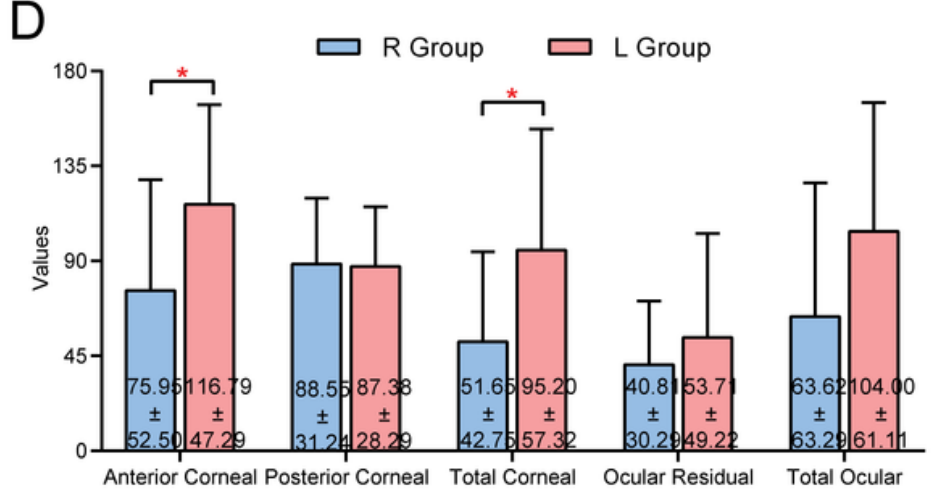

Meridian of R and L Groups' Astigmatism Post-operation

\section{Figure 2}

Pre- or postoperative astigmatism in the anterior cornea, posterior cornea, total cornea; non-corneal ocular residual astigmatism; and total ocular astigmatism in the $\mathrm{R}$ and $\mathrm{L}$ Groups. A: Pre-operative magnitude of astigmatism in the two groups; B: Pre-operative meridian of astigmatism in the two groups; C: Postoperative magnitude of astigmatism in the two groups; D: Post-operative meridian of astigmatism in the two groups. *statistically significant difference was found. 

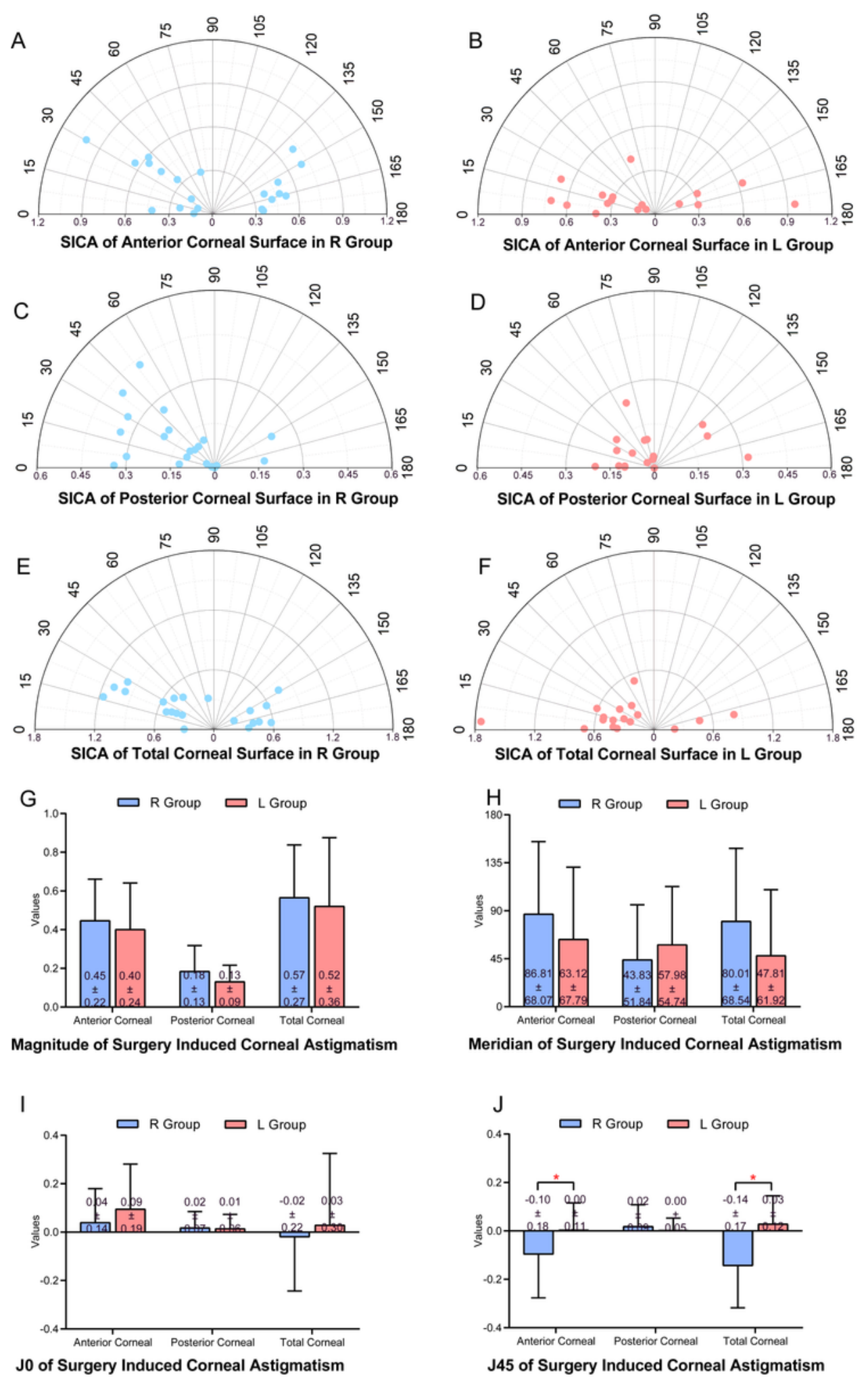

J0 of Surgery Induced Corneal Astigmatism

\section{Figure 3}

Surgically induced corneal astigmatism in the anterior cornea, posterior cornea, total cornea; non-corneal ocular residual astigmatism; and total ocular astigmatism in R and L Groups. A-F: Surgically induced corneal astigmatism in the anterior, posterior, and total corneal surface of the R group $(A, C$, and $E)$ and $L$ group ( $B, D$, and $F$ ) on polar diagrams. $G$ : Magnitude of surgically induced corneal astigmatism in the two groups; H: Meridian of surgically induced corneal astigmatism in the two groups; I: J0 of surgically 
induced corneal astigmatism in the two groups; J: J45 of surgically induced corneal astigmatism in the two groups. *statistically significant difference was found.

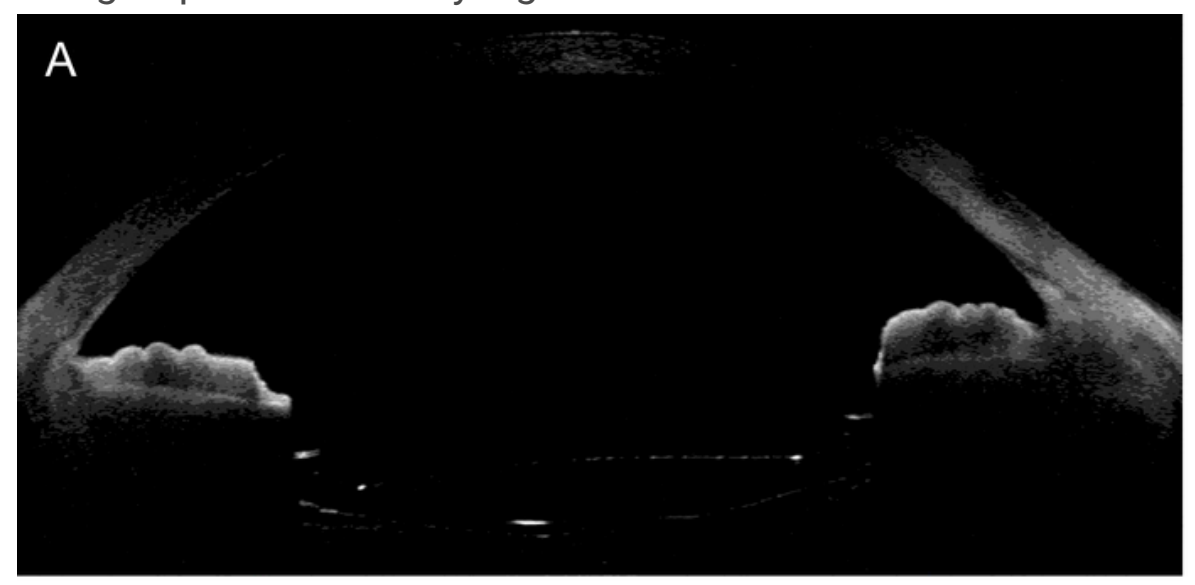

3D angle analysis scan of IOL using AS-OCT

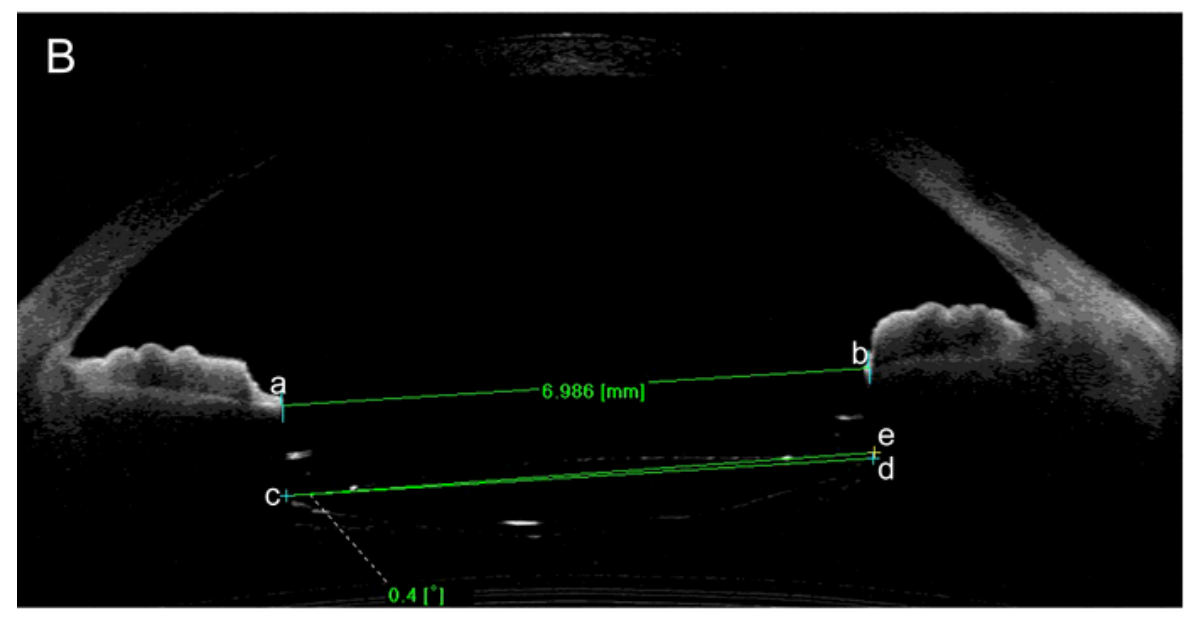

The measurement process of IOL tilt

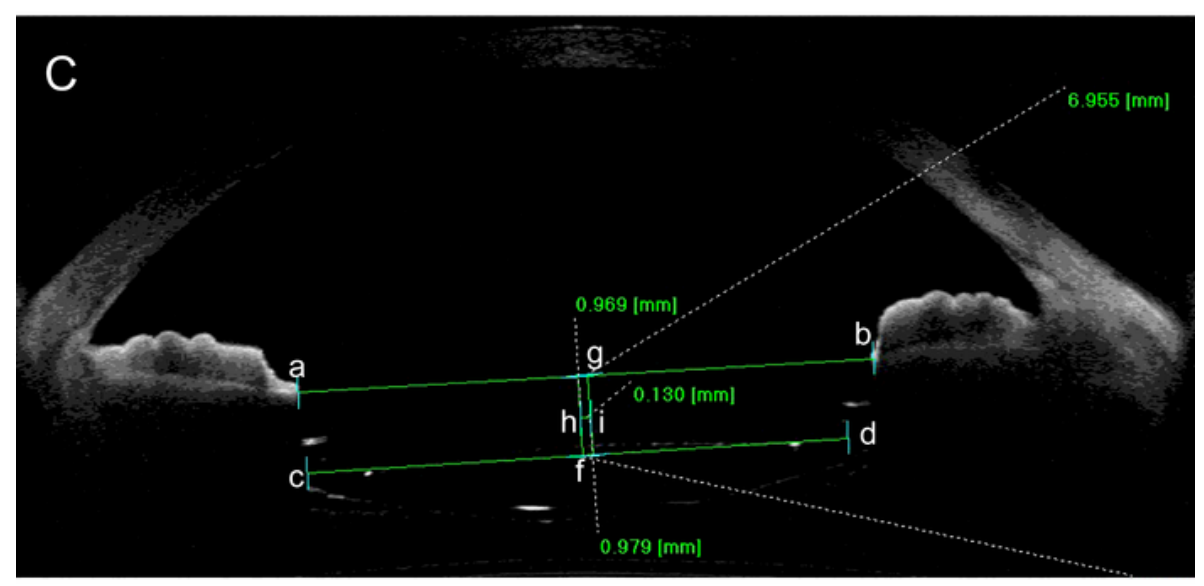

The measurement process of IOL decentration

\section{Figure 4}

Measurement process of the intraocular lens decentration and tilt. A: A 3D angle analysis scan of the intraocular lens using AS-OCT, which presented the anterior and posterior surfaces of the intraocular lens and the position of the iris. B: The line formed by points $a$ and $b$ represents the iris plane. The line formed 
by points $c$ and e represent the intraocular lens plane. The line formed by points $c$ and $d$ is the line parallel to the iris plane. The angle formed by the connection between points $\mathrm{c}$ and $\mathrm{d}$ and the connection between points $\mathrm{c}$ and $\mathrm{e}$ was recorded as the intraocular lens tilt angle. C: Two straight lines perpendicular to the iris and intraocular lens plane through points $g$ and $f$, respectively. The distance between the two vertical lines (presented as the line formed by points $\mathrm{h}$ and $\mathrm{i}$ ) is the intraocular lens decentration. 